\title{
NEUROSCIENCE PERSPECTIVES FOR SCIENCE AND MATHEMATICS LEARNING IN TECHNOLOGY-ENHANCED LEARNING ENVIRONMENTS
}

\section{EDITORIAL}

\section{Received: 7 April 2014; Accepted: 7 April 2014}

Recently, neuroscience perspectives on human learning have drawn increasing interest among researchers in education (Schrag, 2011). Many researchers, particularly in science and mathematics education, have highlighted the utility of integrating a neuroscience or cognitive-science perspective into science and mathematics learning (e.g. Anderson, 1983, 1997, 2009; Anderson \& Contino, 2013; Duncan \& Rivet, 2013; Kwon \& Lawson, 2000; Lawson, 1986, 2003, 2004; Longo, Anderson \& Wicht, 2002). At the same time, another mainstream of productive research has focused on using technology to enhance science and mathematics learning based on research studies and evidence-based improvement of classroom practices derived from the research. In these approaches, multimedia representations such as text, graphic, video, animation, and simulation are usually designed to include concrete cognitive representations, or improved visualizations of abstract and conceptual ideas, as a way of enhancing learning (Chang \& Linn, 2013). Recently, with the rapid development of information technology, some highly innovative approaches have been developed. These include complex digital learning environments and other interactive media, such as web-based learning, mobile learning, game-based learning, and computer-supported collaborative learning. These newer innovations have been critically analyzed and examined in research studies on science and mathematics learning (e.g. Lee, Tsai, Wu, Tsai, Liu, Huang, Lai et al., 2011). Although researchers in different domains have committed substantial efforts in designing innovative learning environments and examining their impacts on students' learning, many challenges remain, such as fully understanding how students perceive and process a variety of representations embedded in different complex learning environments.

Neuroscience methodologies have been recently linked to research in the educational technology field. For example, eye movement methodology has been applied to multimedia learning and the results have been discussed and summarized in some published special issues (e.g. Van Gog \& Scheiter, 2010). Lai, Tsai, Yang, Hsu, Liu, Lee, Lee et al. (2013) also reviewed eye-tracking studies related to learning and pointed out 
several research trends of increasing interest. These include re-examining existing learning theories and investigating effects of instructional design and students' information processing strategies on learning. In science and mathematics domains, several studies have used eye-movement data to understand the interactions between cognitive processes and learning outcomes (Canham \& Hegarty, 2010; Jarodzka, Scheiter, Gerjets \& van Gog, 2010; She \& Chen, 2009; Tsai, Hou, Lai, Liu \& Yang, 2012). Another complementary trend toward this kind of integration of modern cognitive science with learning is to employ learning materials commonly used in real-world contexts in laboratory-based experimental studies. Neuroscience perspectives and methodologies, coupled with cognitive sciences, have gradually created a new domain in educational studies, especially for science and mathematics education researchers who are eager to examine more deeply the influences and limitations of the use of educational technology.

This special issue provides a focused theme on some current progresses in, and perspectives on, the application of neuroscience and cognitive science to enhance research strategies in science and mathematics learning. This special issue aims to present how science and mathematics education researchers utilize neuroscience methodologies, including current thinking about the relationship between neuroscience theory and experimental analyses, in relation to science and mathematics learning, especially in technology-enhanced learning environments. Nine papers encompassing six empirical studies and three review papers are included in this special issue. Below is a brief summary and discussion of the contributions forming this special issue.

As an introduction to this special issue, Anderson (2014) reviews current issues and challenges in the progress toward developing comprehensive neuroscientific-based theories of human learning in complex learning environments. Some large-scale issues and conceptual problems involved in developing a middle-ground "neuroeducational theory" are analyzed, especially for mathematics and science learning. A framework depicting the challenges of synthesizing such a middle-ground neuroeducational theory is presented based on a need to merge the findings from macro- to microlevels of complexity within the neuroscientific and sociocognitive research domains. Perspectives on possible future approaches and challenges in reaching the goal of a neuroeducational theory are presented, including applying new techniques such as eye-tracking, EEG, and AMRI analyses to further understand individual differences in student brain functions while performing some typical cognitive functions in math and science learning, such as problem solving, self-directed learning, and interaction with digital-based learning environments. All other 
subsequent papers in this special issue fall in two categories: eye-tracking studies and brain-based studies.

\section{EYE-TRACKING STUDIES}

Neuroscientific research on visual processing has made significant gains in recent decades, and the use of eye tracking technology has been particularly effective in providing empirical evidence of how visual information processing, mediated by visual processing centers of the brain, relate to learning in general, and particularly in mathematics and science. Several contributions to this special issue have utilized eye tracking in experimental studies to elucidate some important questions that have previously been examined largely by more established approaches.

Learning from science reading is one of the main streams in science education for decades. Ariasi \& Mason (2014) utilize eye-tracking techniques to reveal how undergraduate students read different types of scientific texts, refutation text versus non-refutation text, and link the eye-fixation data to reading outcomes. Particularly, they examine the role of working memory capacity and report an interaction with science text structure. Their results show that working memory capacity is the only predictor of learning from nonrefutation text; while students' prior knowledge, scientific conceptions and total reading time can predict students' learning from refutation text. Using refutation text for reading in science education has been recommended for facilitating conceptual change in science learning. This study shows the interplay of science text structure and working memory capacity by eye-tracking techniques, which successfully links covert brain-based processes with overt outcomes of science text reading.

The role of prior knowledge (PK) in science learning and thinking has been a major focus of research in science education and has largely drawn on theories from the cognitive sciences as a research context. Ho, Tsai, Wang \& Tsai (2014) have combined eye-tracking technology and online learning about greenhouse gases and climate change to provide more in-depth insights how PK influences selective attention to text versus graphic information in online science learning. Their results indicate, among other findings, that high PK students used more inter-scanning transitions among text, graphics, and the data diagrams than low PK students, suggesting that the high PK students were more able to integrate text and graphic information, including greater skill in inspecting scientific data which is essential for online inquiry learning.

Paralleling Ho and her colleagues (2014), but in the domain of equation solving, Susac, Bubic, Kaponja, Planinic \& Palmovic (2014) find that eye movements provide a valuable lens on students' prior knowledge and 
metacognitive strategies. Susac and colleagues find that the number of eye fixations that students make while rearranging algebra equations is a good predictor of solution efficiency. Eye tracking measures suggest that the more knowledgeable students more appropriately directed their attention while manipulating equations. Thus, eye movements provide a way to observe internal cognitive operations that would traditionally be measured offline by self-report. Interestingly, compared to questionnaire data collected from the students, eye movements proved more useful in gauging the solution strategies and expertise of students.

Chen \& Yang (2014) have creatively combined data from spatial relational tests (PVRT) with eye-tracking evidence to explore how students of varying spatial rotational acuity visually process scientific spatial information during online problem solving. They conclude that students with different PVRT acuity employed different problem solving strategies, including evidence that PVRT performance is correlated with eye movement patterns. With respect to science conceptual learning, they found that concept learning was not correlated with PVRT performance, but is more associated with spatial memory and problem solving strategies.

Learning of geometry clearly involves visual information processing in addition to mastery of abstract spatial relationships and their cognate mathematical meanings. Lin \& Lin (2014) approach the challenging problem of better understanding student learning of geometry by combining analyses of eye movements with evidence of cognitive load when students are presented with computer-based geometry problems that vary in levels of configuration. Their findings, of immediate significance for design of geometry diagrams in secondary school mathematics teaching and textbook preparation, indicate that the complexity of the problems and the sequence in which geometric figures of varying complexity are presented can influence the pass rate, including contributions by prior knowledge and the carry-over of information from one problem to the next. Their eye-tracking data indicate that dwell time and frequency of fixation on geometric figures is greater with more difficult problems, including greater use of scanning back and forth as problem complexity increased. Further evidence is presented on the eye scanning strategies of successful compared to unsuccessful problem solvers as well as the relationships between cognitive load and eye movement indicators.

\section{Brain-BASEd StUdies}

Modern research technologies in the neurosciences have substantially improved our knowledge of brain structure and function at increasingly 
finer levels of resolution. Liu \& Chiang (2014) explore some of the implications of recent neuroscientific research employing these technologies to suggest applications for science education research and practice. They explore initially some examples of current progress in the neuroscience of perception and cognition that are relevant to science education. Finally, they conclude with six science concept learning constructs based on "whole brain theory." They particularly emphasize the importance of the integration of cognitive learning theory into the instructional design process. Furthermore, they offer science educators some neuroscience-backed information as a foundation to develop resultsoriented curricula and teaching methods, thus hopefully promoting more integration of cognitive and neuroscientific theory in science education research contributing to the establishment of an empirically driven education system.

As research progresses in basic neuroscience and simultaneously as researchers in educational neuroscience turn their attention toward improving curriculum and instruction, one key challenge will be building linkages between developmental theories, neuroscience methods, and possible instructional interventions. Norton \& DeaterDeckard (2014) consider how neo-Piagetian approaches, which emphasize the psychological operations that enable children to acquire knowledge, can be married with neurological hypotheses. They sketch out how this marriage could be successful in evaluating instructional interventions involving tablet applications and brain measures. By pairing these measurements with a well-matched task, (e.g. an educational game), researchers can gain insight into the psychological operations underlying knowledge reorganization. These insights can be used to guide instruction.

Waisman, Leikin, Shaul \& Leikin (2014) take a step toward cashing out these promising relations between brain measures and instruction. Working with high-school students, they examine the brain correlates of translating between graphical and symbolic representations of mathematical functions. By examining cortical electrical activity (event related potentials, ERPs) during these tasks, they construct theories of how students experience these math problems. Students who were not generally gifted showed the greatest activity during this task, perhaps indicating that this group was experiencing a high cognitive load. The hope is that combining such techniques with more traditional educational research methods will provide a better understanding of the mental processes involved in learning mathematics and mathematical problem solving at both the group and individual levels. 


\section{Conclusion and Future Studies}

Based on the above, this special issue collects nine papers to reveal the current state of neuroscience perspectives for science and mathematics learning in technology-enhanced learning environments. Beginning with an overview of the theoretical development, Anderson (2014) proposes a neuroeducational perspective on science and mathematics learning and points out the challenges in building this construct from different disciplines. Then, five eye-tracking empirical studies explore reading comprehension and problem solving in relation to several different contexts. These include types of scientific texts (Ariasi \& Mason, 2014), information integrations among text and data diagrams for online inquiry learning (Ho et al., 2014), strategies in solving mathematics algebra equations (Susac et al., 2014), geometry problems (Lin \& Lin, 2014), and scientific spatial problem solving (Chen \& Yang, 2014). Learning variables involve working memory capacity, prior knowledge, spatial ability, and cognitive loading. As for the brain-based studies, two review papers focus on reviews and perspectives on linking neuroscience research (Liu \& Chiang, 2014) and developmental theories (Norton \& DeaterDeckard, 2014). Only one study (Waisman et al., 2014) examines the relations between brain measures and instruction using event-related potentials (ERPs). This reveals that the use of brain-based techniques such as electroencephalograph (EEG) or functional magnetic resonance imaging (fMRI) is still limited in this arena.

In future research, more productive gains can be made by using EEG or fMRI instrumentation to investigate the correlation of brain activity with science and mathematics learning activities. Future studies are also suggested to explore more fully the learning of science and mathematics in complex dynamic digital leaning environments, such as online searching tasks, game-based leaning, online collaborative learning, and visual processing patterns during mobile learning while using digital media such as e-books. In general, more empirical eye-tracking and brain-based studies are still required to enhance our understanding of how students process information in complex and dynamic digital learning environments. This in turn may provide a theoretical framework to design individualized scaffoldings for science and mathematics learners based on individual real-time eye movement and brain-based measures along with data log files tracked in future-adapted digital learning environments. 


\section{REFERENCES}

Anderson, O. R. (1983). A neuromathematical model of human information processing. Journal of Research in Science Teaching, 20, 603-620.

Anderson, O. R. (1997). A neurocognitive perspective on current learning theory and science instructional strategies. Science Education, 81, 67-90.

Anderson, O. R. (2009). Neurocognitive theory and constructivism in science education: A review of neurobiological, cognitive and cultural perspectives. Brunei International Journal of Mathematics and Science Education, 1, 1-32.

Anderson, O. R. (2014). Progress in application of the neurosciences to an understanding of human learning: The challenge of finding a middle-ground neuroeducational theory. International Journal of Science and Mathematics Education, 12(3), 475-492, doi:10.1007/s10763-013-9455-3.

Anderson, O. R. \& Contino, J. (2013). The role of visualization in conceptual learning and conceptual change (Chap. 1 in Section 1: Brain functioning and conceptual change). In K. Finson \& J. Pedersen (Eds.), Visual data and their use in science education (pp. 321). Charlotte: Information Age Publishing.

Ariasi, N. \& Mason, L. (2014). From covert processes to overt outcomes of refutation text reading: The interplay of science text structure and working memory capacity through eye fixations. International Journal of Science and Mathematics Education, 12(3), 493-523, doi:10.1007/s10763-013-9494-9.

Canham, M. \& Hegarty, M. (2010). Effects of knowledge and display design on comprehension of complex graphics. Learning and Instruction, 20, 155-166.

Chang, H.-Y. \& Linn, M. C. (2013). Scaffolding learning from molecular visualizations. Journal of Research in Science Teaching, 50(7), 858-886.

Chen, Y. C. \& Yang, F. Y. (2014). Probing the relationship between process of spatial problems solving and science learning: An eye tracking approach. International Journal of Science and Mathematics Education, 12(3), 579-603, doi:10.1007/s10763-013-9504-y.

Duncan, R. G. \& Rivet, A. (2013). Science learning progressions. Science, 339, 396-397.

Ho, H. N. J., Tsai, M.-J., Wang, C.-Y. \& Tsai, C.-C. (2014). Prior knowledge and online inquiry-based science reading: Evidence from eye-tracking. International Journal of Science and Mathematics Education, 12(3), 525-554, doi:10.1007/s10763-013-9489-6.

Jarodzka, H., Scheiter, K., Gerjets, P. \& van Gog, T. (2010). In the eyes of the beholder: How experts and novices interpret dynamic stimuli. Learning and Instruction, 20, 146-154.

Kwon, Y.-J. \& Lawson, A. E. (2000). Linking brain growth with scientific reasoning ability and conceptual change during adolescence. Journal of Research in Science Teaching, 37(1), 44-62.

Lai, M. L., Tsai, M.-J., Yang, F.-Y., Hsu, C.-Y., Liu, T. C., Lee, S. W. Y., Lee, M.-H., Chiou, G. L., Liang, J. C. \& Tsai, C.-C. (2013). A review of using eye-tracking technology in exploring learning from 2000 to 2012. Educational Research Review, 10, 90-115.

Lawson, A. E. (1986). A neurological model of sensory-motor problem solving with possible implications for higher-order cognition and instruction. Journal of Research in Science Teaching, 23, 503-522.

Lawson, A. E. (2003). The neurological basis of learning, development and discovery: Implications for teaching science and mathematics. Dordrecht: Kluwer.

Lawson, A. E. (2004). Reasoning and brain function. In R. J. Sternberg \& J. P. Leighton (Eds.), The nature of reasoning. New York: Cambridge University Press.

Lee, S. W. Y., Tsai, C.-C., Wu, Y. T., Tsai, M.-J., Liu, T. C., Huang, F. K., Lai, C. H., Liang, J. C., Wu, H. C. \& Chang, C. Y. (2011). Internet-based science learning: A review of journal publications. International Journal of Science Education, 33(14), 1893-1925. 
Lin, J. J. H. \& Lin, S. S. J. (2014). Cognitive load for configuration comprehension in computersupported geometry problem solving: An eye movement perspective. International Journal of Science and Mathematics Education, 12(3), 605-627, doi:10.1007/s10763-013-9479-8.

Liu, C. J. \& Chiang, W. W. (2014). Theory, method and practice of neuroscientific findings in science education. International Journal of Science and Mathematics Education, 12(3), 629-646, doi:10.1007/s10763-013-9482-0.

Longo, P., Anderson, O. R. \& Wicht, P. (2002). Visual thinking networking promotes problem-solving achievement for 9th grade Earth Science students. Electronic Journal of Science Education, 7, 1-50.

Norton, A. \& Deater-Deckard, K. (2014). Mathematics in mind, brain, and education: A neo-Piagetian approach. International Journal of Science and Mathematics Education, 12(3), 647-667, doi:10.1007/s10763-014-9512-6.

Schrag, F. (2011). Does neuroscience matter for education? Educational Theory, 61, 221-236.

She, H. C. \& Chen, Y. Z. (2009). The impact of multimedia effect on science learning: Evidence from eye movements. Computers \& Education, 53(4), 1297-1307.

Susac, A., Bubic, A., Kaponja, J., Planinic, M. \& Palmovic, M. (2014). Eye movements reveal students' strategies in simple equation solving. International Journal of Science and Mathematics Education, 12(3), 555-577, doi:10.1007/s10763-014-9514-4.

Tsai, M.-J., Hou, H. T., Lai, M. L., Liu, W.-Y. \& Yang, F. Y. (2012). Visual attention for solving multiple-choice science problem: An eye-tracking analysis. Computers \& Education, 58(1), 375-385.

Van Gog, T. \& Scheiter, K. (2010). Eye tracking as a tool to study and enhance multimedia learning. Learning and Instruction, 20, 95-99.

Waisman, I., Leikin, M., Shaul, S. \& Leikin, R. (2014). Brain activity associated with translation between graphical and symbolic representations of functions in generally gifted and excelling in mathematics adolescents. International Journal of Science and Mathematics Education, 12(3), 669-696, doi:10.1007/s10763-014-9513-5.

O. Roger Anderson

Mathematics, Science and Technology, Teachers College

Columbia University

525 W. 120th Street, New York, NY, 10027, USA

E-mail: ora@ldeo.columbia.edu

Bradley C. Love

Experimental Psychology

University College London

26 Bedford Way, Room 235, London, UKWC1H OAP

E-mail: b.love@ucl.ac.uk

Meng-Jung Tsai (Corresponding Author)

Graduate Institute of Digital Learning and Education

National Taiwan University of Science and Technology

43, Sec. 4, Keelung Rd., Taipei, 106, Taiwan

E-mail:mjtsai99@mail.ntust.edu.tw 